\title{
Farklı cam iyonomer simanların kompozit ve kompomere olan makaslama bağlanma dayanım kuvvetlerinin karşılaştırıması
}

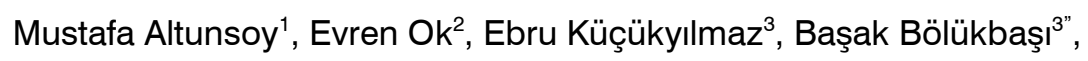 \\ Mehmet Selim Bilgin ${ }^{4}$
}

Selcuk Dental Journal, 2015; 2: 71- 75

Bașvuru Tarihi: 14 Nisan 2015 Yayına Kabul Tarihi: 10 Ağustos 2015

Comparation of the shear bond strength of different glass ionomer cements to compomer and composite

Background: The aim of this study was to compare the shear bond strength (SBS) of four different glass ionomer cements to compomer and composite.

Methods: Eighty cylindrical acrylic blocks with a hole ( $3 \mathrm{~mm}$ in diameter and $2 \mathrm{~mm}$ in height) were prepared. The acrylic blocks were divided into 4 groups and filled with glass ionomer cements (Ionoseal, Ketac Molar, Equia, and Imicryl). Single step self-etch adhesive were applied to surface of glass ionomer cement and polymerized. Each group divided into 2 subgroups $(n=10)$. Compomer and composite were applied over glass ionomer cements by means of a plastic cylinder with a height and diameter each of 2 $\mathrm{mm}$ and polymerized with LED according to the manufacturer's recommendations, from the side of the cylinder. SBS was tested for failure using a knife-edge blade in a universal testing machine. The data were analyzed using Two-Way Analysis of Variance (ANOVA) and Tukey test $(p=0.05)$.

Results: Ionoseal showed significantly higher SBS to compomer and composite than other glass ionomers $(p<0,05)$. There was no statistically differences between SBS of Ketac Molar, Imicryl, and Equia to compomer and composite $(p>0,05)$.

Conclusion: lonoseal showed higher SBS to composite and compomer than Ketac Molar, Equia, and Imicryl.

\section{KEY WORDS}

Compomers, composite resins, glass ionomer cements, shear strength
Cam iyonomer simanlar 1972 yllında ilk olarak üretilmesinden bu yana klinik diş hekimliğinde yaygın bir kullanım alanı bulmuştur (Wilson ve Kent 1972). Cam iyonomer simanın flor salımı, bakteri asit metabolizmasını inhibe edici, biyouyumluluk, mine ve dentine kimyasal bağlanma gibi üstün özellikleri bulunmaktadır (dos Santos, Pithon ve ark. 2010, Flores, Saez ve ark. 1999, Maruo, Godoy-Bezerra ve ark. 2010). Olumlu özelliklerinin yanında cam iyonomer simanın uzun sertleşme süresi, sertleşme başlangıcında neme duyarlı olması, dehidratasyon, estetik ve mekanik özelliklerinin düşük olması gibi dezavantajları bulunmaktadır (Maneenut, Sakoolnamarka ve ark. 2010). Günümüzde, bu materyallerin içeriği değiştirilerek rezin içerikli, yüksek dolduruculu özelliklerde cam iyonomer simanlar üretilmiştir. İçeriği farklı olan cam iyonomer simanların bağlanma mekanizmaları, sertleşme reaksiyonları ve neme olan hassasiyetleri farklı olabilmektedir.

Kompozitler, estetik ve yüksek mekanik özelliklere sahip olmaları nedeniyle diş hekimliğinde yaygın kullanım alanları bulunmaktadır. Ancak kompozitlerin polimerizasyon büzülmesi ve bunun sonucunda da sekonder çürük oluşumu gibi dezavantajları bulunmaktadır (Jandt ve Sigusch 2009). Kompomerler içeriğinde dimetakrilat monomerler ve polikarboksilik asit içeren hem kompozitlerin hem de cam iyonomer simanların özelliklerini taşıyan dental materyallerdir. Kompomerlerin fiziksel özellikleri daha çok kompozitlere benzemektedir ve diş sert dokularına uygulanması kompozitlerle benzerlik göstermektedir (Meyer, Cattani-Lorente ve ark. 1998). Cam iyonomer simanın çürük önleyici,

\footnotetext{
${ }^{1}$ Şifa Üniversitesi Diş Hekimliği Fakültesi Pedodonti Anabilim Dalı, Bayraklı, İzmir

2 Şifa Üniversitesi Diş Hekimliği Fakültesi Endodonti Anabilim Dalı, Bayraklı, İzmir

3 İzmir Katip Çelebi Üniversitesi Diş Hekimliği Fakültesi Pedodonti Anabilim Dalı, Çiğli, İzmir

${ }^{4}$ Şifa Üniversitesi Diş Hekimliği Fakültesi Protetik Diş Tedavisi Anabilim Dalı, Bayraklı, İzmir
} 
dentine kimyasal bağlanma ve biyouyumluluk gibi özellikleri; rezin materyallerin estetik, yüksek mekanik dayanımı gibi özelliklerinden yola çıkılarak kavitelerde bu materyallerin birlikte kullanımı (sandiviç tekniği) tavsiye edilmektedir (Mount, Tyas ve ark. 2009, Tyas 2006). Bu teknik rezin restorasyonun birincil tercih edildiği derin ve madde kaybının fazla olduğu duvarlı kavitelerde uygulabilir. Kayıp dentinin yeri cam iyonomer siman ile restore edilir ve kavitenin kalan kısmı ise rezin restorasyonla tamamlanmaktadır (Pamir, Sen ve ark. 2012). Bu teknikte cam iyonomer simanın dentine olan bağlantısı kadar üzerine yerleştirilen rezin materyale olan bağlantısıda önemli hale gelmektedir. Ayrıca farklı içerikli cam iyonomer simanların rezin materyale olan bağlantısı da farklı olabilmektedir. Bu çalışmanın hipotezi; farklı cam iyonomer simanların kompozit ve kompomer materyallere olan makaslama bağlanma kuvvetleri farklıdır. Bu çalışmanın amacı dört farklı cam iyonomer simanın kompozit ve kompomere olan makaslama bağlanma dayanım kuvvetlerini karşılaştırmaktır.

\section{GEREÇ ve YÖNTEM}

Çalışma için 80 adet silindirik şekilli akrilik blok hazırlandı. Blokların düz yüzeylerinin ortasına 2 $\mathrm{mm}$ derinliğinde ve $3 \mathrm{~mm}$ çapında olan çukurcuklar açıldı. Bloklar rastgele dört gruba ayrılarak açılan çukurcuklar lonoseal (Ionoseal, Cuxhaven, Almanya), Ketac Molar (3M EPSE, Seefeld, Almanya), Equia (GC Avrupa, Tokyo, Japonya) ve İmicryl (Imicryl SC, Imicryl Diş Malz San. Tic. AŞ, Konya, Türkiye) marka cam iyonomer materyalleri ile üretici firma talimatlarına uygun olarak hazırlanarak dolduruldu. Her bir grup cam iyonomer simanların üzerine uygulanacak materyal çeşidine göre (kompozit veya kompomer) 2 alt gruba ayrıldı. Standart yüzeyler elde etmek için sertleşmeden önce cam iyonomerlerin üzeri şeffaf bant ile kapatıldı. Sertleşme tamamlandıktan sonra cam iyonomer siman yüzeylerine tek aşamalı adeziv (Futurabond M, VOCO GmbH, Cuxhaven, Almanya) uygulandı ve LED ışık cihazı ile (Elipar Freelight 3, 3M ESPE, Almanya) polimerize edildi. Her bir cam iyonomerin toz likit oranının ayarlanması, karıştırma süresi, bonding ajanın uygulaması ve polimerizasyon işlemleri üretici firmaların tavsiyeleri doğrultusunda gerçekleştirildi. Hazırlanan yüzeylerin üzerine yerleştirilen $2 \mathrm{~mm}$ yüksekliğinde ve $2 \mathrm{~mm}$ çapındaki silindirik silikon aparatın içerisine taşmayacak şekilde doldurulan kompomer (Imicryl SC, Imicryl Diş Malz San. Tic. AŞ, Konya, Türkiye) ve kompozit (VOCO, Cuxhaven, Almanya) materyalleri üretici firmanın tavsiyeleri doğrultusunda LED ışık cihazı ile polimerize edildi. Örnekler 24 saat süreyle $37^{\circ} \mathrm{C}$ sıcaklık altında bekletildi. Universal test makinesi (Shimadzu, Model AGS-X 5kN, Shimadzu Corporation, Kyoto, Japonya) ile her bir örnekte kırılma meydana gelinceye kadar $1 \mathrm{~mm} / \mathrm{dk}$ hızda kuvvet uygulandı. Newton (N) cinsinden elde edilen değerler materyallerin bağlanma yüzey alanına bölünerek Megapaskal (MPa) cinsinden veriler elde edilmiş oldu. Örneklerin kırılma yüzey alanları steriomikroskop kullanarak $30 \times$ büyütmeyle incelendi.

Örneklerin kırılma modları adeziv, koheziv ve karma olarak sınıflandırıldı. Bağlanma dayanım verileri iki yönlü varyans analizi ve Tukey çoklu karşılaştırma testleri ile istatistiksel olarak değerlendirildi $(p=0.05)$.

\section{BULGULAR}

Ionoseal'in kompomere olan makaslama bağlanma değeri diğer cam iyonomerlerden istatistiksel olarak daha yüksek bulundu $(p<0,05)$. Ketac Molar, Equia ve İmicryl'in kompomere olan makaslama bağlanma değerleri arasında istatistiksel olarak fark gözlenmedi $(p>0,05)$ (Şekil 1).

lonoseal' in kompozite olan makaslama bağlanma değeri diğer cam iyonomerlerden istatistiksel olarak daha yüksek bulundu $(p<0,05)$. Ketac Molar, Equia ve Imicryl' in kompozite olan makaslama bağlanma değerleri arasında istatistiksel olarak fark gözlenmedi $(p>0,05)$. Kompozit ve kompomerin cam iyonomerlere bağlanma dayanım değerleri arasında istatistiksel olarak fark gözlenmedi $(p>0,05)$ (Şekil 1).

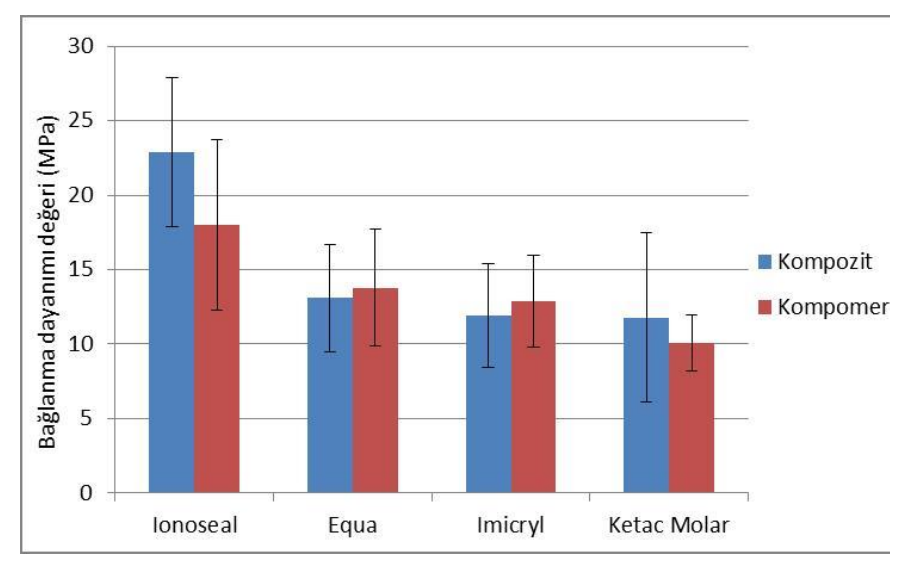

Şekil 1.

Gruplara ait makaslama bağlanım değerleri (ortalama, standart sapma)

Örneklerde en fazla koheziv kırılma (cam iyonomer materyalleri içerisinde) daha sonra karma kırılma ve en düşük ise adeziv kırılma gözlendi (Resim 1) (Şekil 2, 3). 


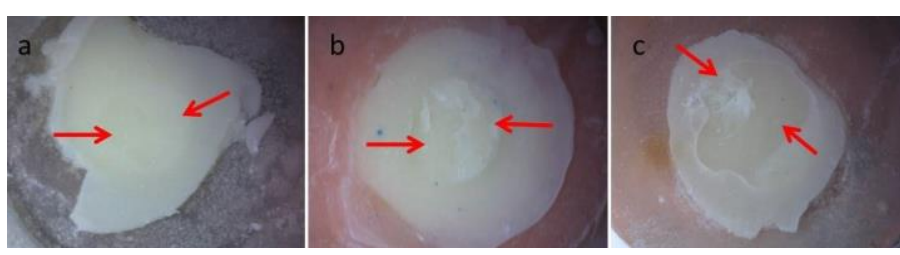

Resim 1.

Kırılma tiplerine ait stereomikroskop görüntüleri

a) Adeziv kırılma

b)Koheziv kırılma

c) Karma (adeziv/koheziv) kırılma

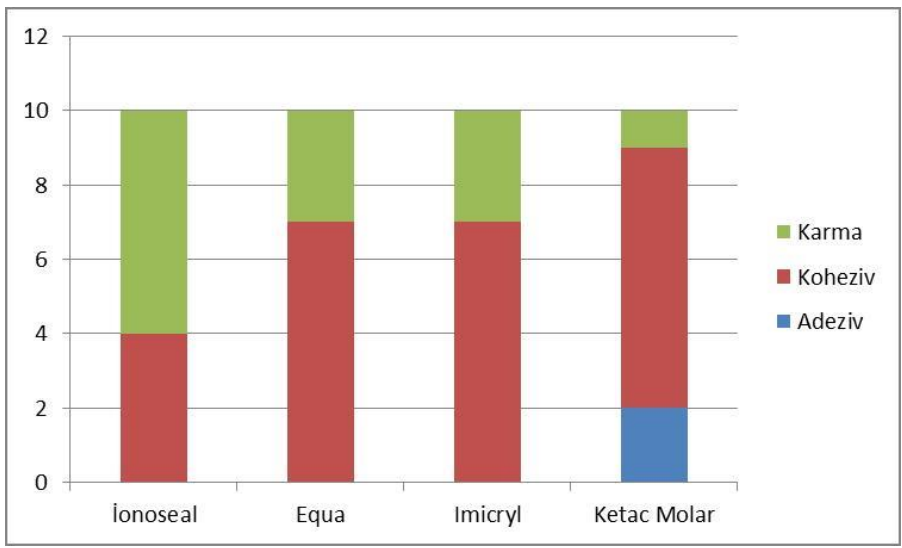

Şekil 2.

Kırılma tiplerinin gruplara göre dağılımı (kompomer için)

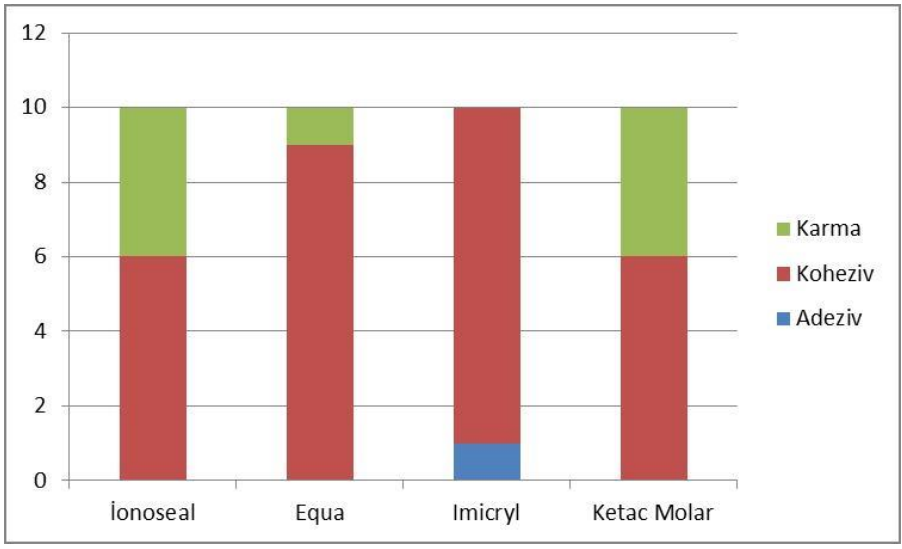

Şekil 3.

Kırılma tiplerinin gruplara göre dağılımı (kompozit için)

\section{TARTISSMA}

Kompozit rezinlerde büyük gelişme olmasına rağmen bu materyallerde meydana gelen polimerizasyon büzülmesi hala çözülememiştir. $\mathrm{Bu}$ durumu engellemek için kavitede kullanılan rezin materyalin miktarını azaltmak için genellikle cam iyonomer siman kullanılmaktadır. Bu şekilde polimerizasyon büzülmesi engellenmiş olacaktır ve dolayısıyla diş-dolgu arayüzündeki mikrosızıntı ve mikroaralık azalacaktır (Goldman 1983). Rezin restorasyonların altında kaide olarak kullanılan cam iyonomer simanın diş dokularına olan bağlantısının önemi kadar kompozit rezine olan bağlantısı da kabul edilebilir sınırlarda olmalıdır (Hinoura, Suzuki ve ark. 1991). Bu yüzden restorasyonun başarısının artması için sandiviç tekniğinde en uygun Cis'nin kullanılması gerekmektedir.

Bazı çalışmalarda rezin içerikli cam iyonomer simanların geleneksel cam iyonomer simanlardan kompozite daha yüksek bağlandığı bildirilmiştir (Kerby ve Knobloch 1992, Navimipour, Oskoee ve ark. 2012). Bu çalışmada ionosealin kompozit ve kompomere olan makaslama bağlanma dayanım değeri diğer cam iyonomerlerden daha yüksek olduğu gözlendi. Bu nedenle çalışmanın hipotezi kabul edilmiştir. Ketac Molar, Imicryl ve Equa toz ve likit karışımıyla başlayan bir asit-baz reaksiyonuyla sertleşmektedirler. Ionoseal rezin esaslı bir cam iyonomer simandır ve ışıkla polimerizasyon başlamaktadır ve simanın sertleşmesi kimyasal olarak devam etmektedir. lonoseal' in içeriğinde metakrilat monomerlerin olması ve içeriğinin dental bonding, kompozit ve kompomer materyallerine benzemesi bulunan yüksek bağlanma dayanımını açıklayabilmektedir. Ayrica polimerizasyondan sonra ionosealin yüzeyindeki oksijen inhibisyon tabakası adı verilen polimerize olmamış artık monomerlerin bulunduğu bir tabaka bulunmaktadır. Bu tabaka, üzerine uygulanan bonding ajan ile güçlü kovalent bağ oluşturarak bağlantıyı arttırmaktadır (Kerby ve Knobloch 1992).

Kırıma analizi dental materyallerin bağlantısı hakkında bilgi verebilmektedir (Rinastiti, Özcan ve ark. 2010). İki materyal arasında meydana gelen koheziv kırılma yüksek bağlantı olduğunun 
göstergesidir (Özer, Şen Tunç ve ark. 2014). Çalışmamızda değerlendirilen materyallerde en çok koheziv kırılma tipi ve bunu takiben karma kırılma gözlenmiştir. Sadece 3 örnekte adeziv tip kırılma gözlenmiştir. Buradan da anlaşılıyor ki kullandığımız cam iyonomer simanların kompozit ve kompomere olan makaslama bağlanma dayanımı yeterli düzeydedir.

Çalışmamızda kullanılan her bir cam iyonomer simanın kompozit ve kompomere olan makaslama bağlanma dayanımı arasında istatistiksel olarak fark olmadığı gözlendi. Bu durum örneklerin önemli bir bölümünde meydana gelen koheziv ve karma kırılma ile açıklanabilir. Çünkü bu kırılma tipleri cam iyonomer materyaller içerisinde meydana gelmiştir ve dolayısıyla çalışmamızdan elde ettiğimiz bağlanma değerleri kompozit ve kompomerin cam iyonomer arayüzündeki bağlanma dayanım değerini tam olarak yansıtmayabilir.

Bu çalışmada, Equa'nın rezin materyallere olan makaslama bağlanma dayanımı Ketac Molar ve Imicryl' den daha yüksek olduğu gözlendi ancak bu fark istatistiksel olarak önemsiz bulundu. Bu durumun cam iyonomerlerin içeriklerinin farklı olmasından ve karıştırma prosedürlerinin farklılığından kaynaklandığını düşünmekteyiz. Equa yüksek viskoziteli kapsül cam iyonomer simandır ve amalgamatörle karıştırılmaktadır. Ketac Molar ve Imicryl elle karıştırılan cam iyonomer simanlardır. Elle karıştırılan cam iyonomer simanlarda toz-likit oranının ayarlanamaması, karıştırma süresi, karıştırma zamanı ve simanı karıştırdıktan sonra kaviteye yerleştirmek için geçen süre simanın mekanik özelliklerini etkileyebilmektedir (Molina, Cabral ve ark. 2013). Molina ve ark. (Molina, Cabral ve ark. 2013) kapsül ve elle karıştırılan cam iyonomerlerin mekanik özelliklerini inceledikleri çalışmalarında Equia'nın mekanik özelliklerinin Ketac Molar Easymix cam iyonomerden daha yüksek olduğunu bildirmişlerdir.

Çalışmamızda çeşitli cam iyonomer simanların kompomer ve kompozite olan makaslama bağlanma dayanımları incelendi. Ancak cam iyonomer simanların diş sert dokularına bağlantısı da önem teşkil etmektedir; bu yüzden gelecekte bu konu üzerine çalışma yapılması gerektiğini düşünmekteyiz.

\section{SONUÇ}

Rezin esaslı cam iyonomer siman olan lonoseal kimyasal sertleşen Ketac Molar, Equia ve İmicryl cam iyonomer simanlara göre daha yüksek makaslama bağlanma değeri göstermektedir.
Farklı cam iyonomer simanların kompozit ve kompomere olan makaslama bağlanma dayanım kuvvetlerinin karşılaştırıması

Amaç: $\mathrm{Bu}$ çalışmanın amacı dört farklı cam iyonomer simanın kompozit ve kompomere olan makaslama bağlanma dayanımlarını karşılaştırmaktır.

Gereç ve Yöntemler: Çalışma için 80 adet silindirik şekilli akrilik blok hazırlandı. Blokların düz yüzeylerinin ortasına $2 \mathrm{~mm}$ derinliğinde ve $3 \mathrm{~mm}$ çapında olan çukurcuklar açıldı. Bloklar dört gruba ayrılarak açılan çukurcuklar Ionoseal (lonoseal, Cuxhaven, Almanya), Ketac Molar (3M EPSE, Seefeld, Almanya), Equia (GC Avrupa, Tokyo, Japonya) ve İmicryl (Imicryl SC, Imicryl Diş Malz San. Tic. AŞ, Konya, Türkiye) marka cam iyonomer materyalleri ile dolduruldu. Standart yüzeyler elde etmek için sertleşmeden önce cam iyonomerlerin üzeri şeffaf bant ile kapatıldı. Sertleşme tamamlandıktan sonra cam iyonomer siman yüzeylerine tek aşamalı adeziv (Futurabond $\mathrm{M}$, VOCO $\mathrm{GmbH}$, Cuxhaven, Almanya) uygulandı ve polimerize edildi. Her bir grup 2 alt gruba ayrıldı. Hazırlanan yüzeylerin üzerine yerleştirilen $2 \mathrm{~mm}$ yüksekliğinde ve $2 \mathrm{~mm}$ çapındaki aparatın içerisine taşmayacak şekilde doldurulan kompomer (Imicryl SC, Imicryl Diş Malz San. Tic. AŞ, Konya, Türkiye) ve kompozit (VOCO, Cuxhaven, Almanya) materyalleri üretici firmaların tavsiyeleri doğrultusunda LED ışık cihazı ile polimerize edildi. Universal test makinesi ile her bir örnekte kırılma meydana gelinceye kadar kuvvet uygulandı. Veriler iki yönlü varyans analizi ve Tukey çoklu karşılaştırma testleri ile istatistiksel olarak değerlendirildi $(p=0.05)$.

Bulgular: Ionoseal' in kompozit ve kompomere olan makaslama bağlanma değeri diğer cam iyonomerlerden istatistiksel olarak daha yüksek bulundu ( $p<0,05)$. Ketac Molar, Equia ve İmicryl' in kompozit ve kompomere olan makaslama bağlanma değerleri arasında istatistiksel olarak fark gözlenmedi ( $p>0,05)$.

Sonuç: Rezin esaslı cam iyonomer siman olan Ionoseal kimyasal sertleşen Ketac Molar, Equia ve İmicryl cam iyonomer simanlara göre daha yüksek makaslama bağlanma değeri göstermektedir.

\section{ANAHTAR KELIMELER}

Cam iyonomer simanlar, kompomerler, kompozitler, makaslama bağlanım kuvveti 


\section{KAYNAKLAR}

dos Santos, R. L., M. M. Pithon, D. S. Vaitsman, M. T. Araujo, M. M. de Souza ve M. G. Nojima 2010. "Long-term fluoride release from resin-reinforced orthodontic cements following recharge with fluoride solution." Braz Dent J 21(2): 98-103.

Flores, A. R., E. G. Saez ve F. Barcelo 1999. "Metallic bracket to enamel bonding with a photopolymerizable resin-reinforced glass ionomer." Am J Orthod Dentofacial Orthop 116(5): 514-517.

Goldman, M. 1983. "Polymerization shrinkage of resin-based restorative materials." Aust Dent J 28(3): 156-161.

Hinoura, K., H. Suzuki ve H. Onose 1991. "Factors influencing bond strengths between unetched glass ionomers and resins." Oper Dent 16(3): 90-95.

Jandt, K. D. ve B. W. Sigusch 2009. "Future perspectives of resin-based dental materials." Dent Mater 25(8): 1001-1006.

Kerby, R. E. ve L. Knobloch 1992. "The relative shear bond strength of visible light-curing and chemically curing glass-ionomer cement to composite resin." Quintessence Int 23(9): 641-644.

Maneenut, C., R. Sakoolnamarka ve M. J. Tyas 2010. "The repair potential of resin-modified glassionomer cements." Dent Mater 26(7): 659-665.

Maruo, I. T., J. Godoy-Bezerra, A. Y. Saga, O. M. Tanaka, H. Maruo ve E. S. Camargo 2010. "Effect of etching and light-curing time on the shear bond strength of a resin-modified glass ionomer cement." Braz Dent J 21(6): 533-537.

Meyer, J. M., M. A. Cattani-Lorente ve V. Dupuis 1998. "Compomers: between glass-ionomer cements and composites." Biomaterials 19(6): 529539.

Molina, G. F., R. J. Cabral, I. Mazzola, L. B. Lascano ve J. E. Frencken 2013. "Mechanical performance of encapsulated restorative glass-ionomer cements for use with Atraumatic Restorative Treatment (ART)." J Appl Oral Sci 21(3): 243-249.

Mount, G. J., M. J. Tyas, J. L. Ferracane, J. W. Nicholson, J. H. Berg, R. J. Simonsen ve H. C. Ngo 2009. "A revised classification for direct toothcolored restorative materials." Quintessence Int 40(8): 691-697.
Navimipour, E. J., S. S. Oskoee, P. A. Oskoee, M. Bahari, S. Rikhtegaran ve M. Ghojazadeh 2012. "Effect of acid and laser etching on shear bond strength of conventional and resin-modified glassionomer cements to composite resin." Lasers Med Sci 27(2): 305-311.

Özer, S., E. Şen Tunç ve N. Gonulol 2014. "Bond strengths of silorane- and methacrylate-based composites to various underlying materials." Biomed Res Int 2014: 782090.

Pamir, T., B. H. Sen ve O. Evcin 2012. "Effects of etching and adhesive applications on the bond strength between composite resin and glass-ionomer cements." J Appl Oral Sci 20(6): 636-642.

Rinastiti, M., M. Özcan, W. Siswomihardjo ve H. J. Busscher 2010. "Immediate repair bond strengths of microhybrid, nanohybrid and nanofilled composites after different surface treatments." J Dent 38(1): 2938.

Tyas, M. J. 2006. "Clinical evaluation of glassionomer cement restorations." J Appl Oral Sci 14 Suppl: 10-13.

Wilson, A. D. ve B. E. Kent 1972. "A new translucent cement for dentistry. The glass ionomer cement." $\mathrm{Br}$ Dent J 132(4): 133-135.

\section{Yazışma Adresi:}

Yrd. Doç. Dr. Mustafa Altunsoy

Şifa Üniversitesi Diş Hekimliği Fakültesi

Pedodonti AD

Bayraklı, İzmir

Tel: +90 (232) 4864140

Faks: +90 (232) 4864147

E-mail:dtaltunsoy@gmail.com 